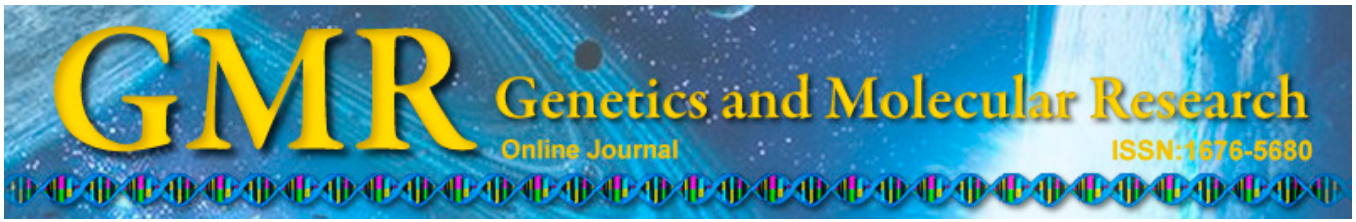

\title{
Simple sequence repeat-based analysis of the genetic diversity and population genetic structure of populations of Siniperca chuatsi
}

\author{
C.F. Sun, X. Ye, Y.Y. Tian and J.J. Dong \\ Key Laboratory of Tropical and Subtropical Fisheries Resource Application \\ and Cultivation of China Ministry of Agriculture, Pearl River Fisheries Institute, \\ Chinese Academy of Fishery Sciences, Guangzhou, China \\ Corresponding author: $\mathrm{X}$. Ye \\ E-mail: gzyexing@163.com
}

Genet. Mol. Res. 14 (3): 9343-9352 (2015)

Received January 8, 2015

Accepted May 11, 2015

Published August 10, 2015

DOI http://dx.doi.org/10.4238/2015.August.10.15

\begin{abstract}
In order to provide genetic information for the selective breeding of Siniperca chuatsi, 14 microsatellite DNA loci were used to evaluate the genetic diversity and structure of four farmed populations and one wild population in China. The four cultivated populations were Foshan (FS), Jiangmen (JM), Nanjing (NJ), and Hongze Lake (HZL), and the wild population was collected from the Hubei HuangGang section of the Yangtze River (HG). All five populations exhibited high genetic diversity $\left(H_{\mathrm{E}}\right.$ values of between 0.608 and 0.633$)$; the highest was found in the wild population $\left(H_{\mathrm{E}}=0.633\right)$. Genetic differentiation within the populations was relatively low $\left(F_{\mathrm{ST}}<0.15\right) ; 5.44 \%$ of the genetic variation was between the populations and $94.56 \%$ was within the populations. The greatest genetic distance was between JM and HG (0.1894), which had the lowest genetic identity (0.8725). NJ and HG had the shortest genetic distance (0.0365) and the highest genetic identity (0.9641). A phylogenetic analysis revealed that FS, JM, and
\end{abstract}


HZL were clustered into one group, while NJ and HG were in another group, suggesting that the wild and NJ populations were closely related. Our results demonstrate that although the farmed populations have maintained a relatively high genetic diversity, they exhibit lower genetic diversity and higher genetic differentiation than the wild population. These results provide evidence that wild resources should be used for breeding, in order to maintain genetic diversity and ensure sustainable $S$. chuatsi farming.

Key words: Microsatellite; Siniperca chuatsi; Genetic diversity; Genetic structure; Genetic similarity; Genetic distance

\section{INTRODUCTION}

Siniperca chuatsi (Basilewsky), commonly known as the Mandarin fish, Aukua, or season flower fish, is widely distributed in major Chinese river and lake systems (Fang and Chong, 1932; Zhou et al., 1988). It is an important freshwater fish species in China, and is in high demand by domestic and international markets (Zhao et al., 2008; Chen et al., 2012). S. chuatsi has been farmed since the early 1970s in several provinces in China, including Guangdong, Jiangsu, Hubei, and Jianxi. Its annual yield in China is about 300,000 tons; Guangdong Province alone produces 100,000 tons. Recently, there has been a decline in the growth rate of pond-cultured $S$. chuatsi, a shortened period of sexual maturity, and reduced anti-disease ability, which seriously affect the quality and safety of the product (He et al., 2002). It is thought that this is due to germplasm degeneration, which results in decreased disease resilience in the offspring. Therefore, understanding the genetic diversity of the existing farmed populations of $S$. chuatsi can provide a scientific basis for selective breeding and germplasm resource protection.

DNA-based molecular markers can accurately identify genetic traits and information, and have greatly assisted in the development of plant and animal genetic breeding (Kumar et al., 2009). Microsatellite DNA, also known as simple sequence repeats (SSRs) or simple tandem repeats (STRs), is one of the most widely used markers (Powell et al., 1996). Microsatellite DNA is widely used in germplasm protection and genetic and quantitative trait locus mapping because of its wide distribution in the genome, high polymorphism rate, and co-dominant inheritance, and is easy to analyze (Zane et al., 2002; Liu and Cordes, 2004; Chauhan and Rajiv, 2010).

Recently, studies on the genetic diversity of $S$. chuatsi have been conducted. For example, using the random amplified polymorphic DNA (RAPD) technique, Fang et al. (2005) demonstrated that a wild population of $S$. chuatsi had high genetic diversity, while genetic diversity in a farmed population was significantly lower. Yu et al. (2012) analyzed sequences of mitochondrial DNA and found that the genetic diversity of farmed populations in Hunan and Hubei were higher than that of a Guangdong farmed population. Mei et al. (2010) used 20 microsatellite loci to analyze a Hunan original population and a Xiang River farmed population. The results revealed that the original population had higher genetic diversity than the farmed population. Tian et al. (2013) examined the genetic structure and diversity of five populations of $S$. chuatsi from the middle reaches of the Yangtze River using mitochondrial cytochrome $\mathrm{b}$ sequences and microsatellite markers. They found that the populations had high genetic diversity and low genetic differentiation (Tian et al., 2013). 
Guangdong Province is the most important area for $S$. chuatsi farming, as well as for fry production, and provides many provinces around the country with Mandarin fish and fry. However, selectively breeding S. chuatsi for a better growth performance or anti-disease ability has not occurred. Guangdong and Jiangsu provinces produce most of the farmed Mandarin fish in China, and account for nearly half of the country's production. HuangGang contains most of the wild Mandarin fish in China. Therefore, it is necessary to investigate the genetic diversity of $S$. chuatsi farmed in Guangdong as well as in other main farming areas, in order to provide a scientific basis for selective breeding. In this study, using microsatellite markers we analyzed the genetic structure and diversity of four farmed populations of $S$. chuatsi from Guangdong Province and other areas, including Foshan (FS), Jiangmen (JM), Nanjing (NJ), and Hongze Lake (HZL), and one wild population from the Huanggang (HG) section of the Yangtze River.

\section{MATERIAL AND METHODS}

\section{S. chuatsi samples}

Farmed S. chuatsi were obtained from FS, JM, NJ, and HZL. Wild S. chuatsi were obtained from the Yangtze River in HG (Figure 1). Fin tissues from each fish were placed in $95 \%$ ethanol for DNA isolation.

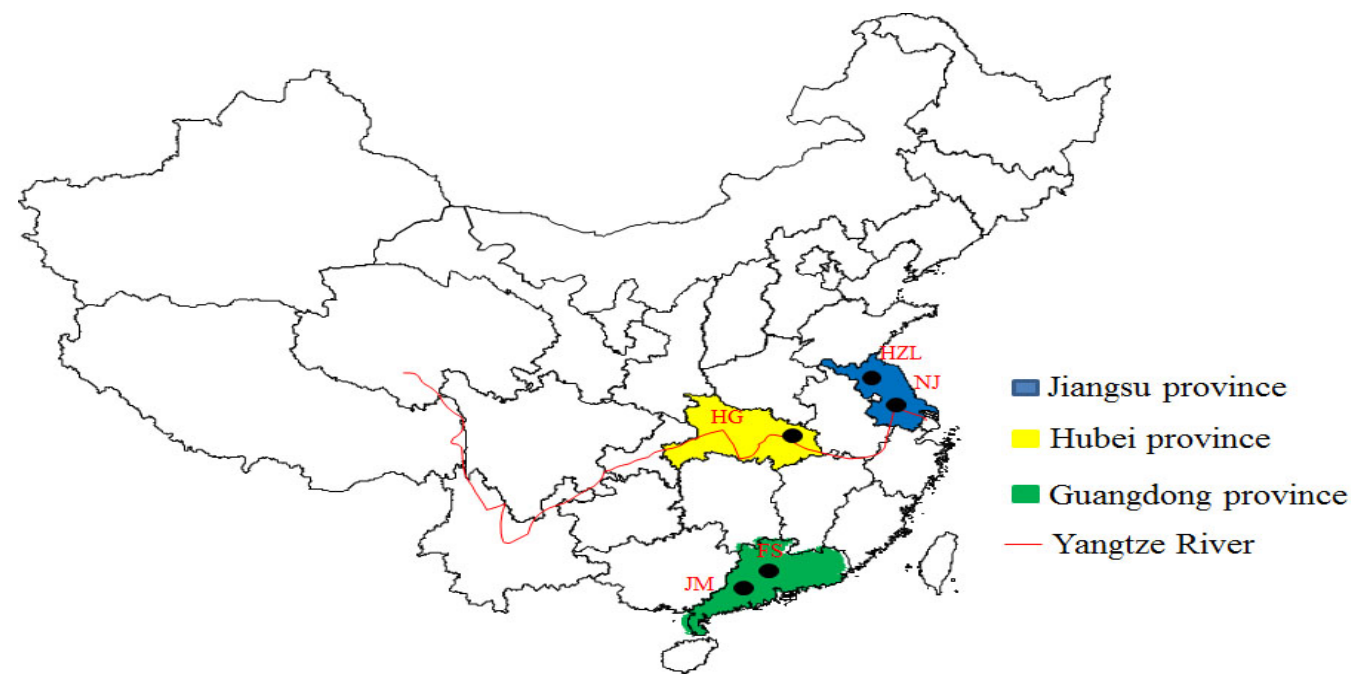

Figure 1. Sampling locations of Siniperca chuatsi populations in China. Foshan (FS), Jiangmen (JM), Nanjing (NJ), Hongze Lake (HZL), Yangtze River in Huanggang segment (HG).

\section{Selection of microsatellite primers and DNA isolation}

Based on the microsatellite DNA sequences of S. chuatsi registered in GenBank, we chose 30 pairs of primers and selected 14 pairs with high specificity, reproducibility, and polymorphisms (Table 1) (Liu et al., 2011; Qu et al., 2012). Each primer was labeled with a florescence probe (FAM, ROX, or HEX) in order to estimate the size of the amplified frag- 
ments. Total DNA was isolated using a Tiangen Genomic DNA Extraction Kit (Tiangen, Beijing, China). Quality and quantity of DNA were analyzed by agarose gel electrophoresis and a spectrophotometer.

\begin{tabular}{|c|c|c|c|c|c|c|c|}
\hline & Primer name & Repeat sequence & Primer sequence & $\begin{array}{l}\text { Production } \\
\text { size }\end{array}$ & $\begin{array}{l}\mathrm{Tm} \\
\left({ }^{\circ} \mathrm{C}\right)\end{array}$ & $\begin{array}{l}\text { No. of } \\
\text { alleles }\end{array}$ & $\begin{array}{l}\text { Accession } \\
\text { No. }\end{array}$ \\
\hline 1 & $\operatorname{Sin} 112$ & $(\mathrm{AC})_{15}$ & $\begin{array}{l}\text { F: FAM-ATCGGCACCTGAGGCAAAAG } \\
\text { R: GCCATCCATAGAGCCACGTC }\end{array}$ & $132-166$ & 54.5 & 6 & JQ804768 \\
\hline 2 & $\operatorname{Sin} 116$ & $(\mathrm{TG})_{14}(\mathrm{AG})_{7}$ & $\begin{array}{l}\text { F: FAM-ACAATCCCAGCCCTCCTTCT } \\
\text { R: GCAAGGTCCCTTTACATGCAG }\end{array}$ & $212-265$ & 54.5 & 6 & JQ804771 \\
\hline 3 & $\operatorname{Sin} 130$ & $(\mathrm{GTGA})_{7} \mathrm{~N}_{7}(\mathrm{TG})_{8}$ & $\begin{array}{l}\text { F: FAM-CTCGCAGGCTTTTCTCTGCT } \\
\text { R: AGCCATCAGTTCTGTTCTTTCTT }\end{array}$ & $282-300$ & 54.5 & 2 & JQ804785 \\
\hline 4 & $\operatorname{Sin} 134$ & $(\mathrm{TG})_{14}$ & $\begin{array}{l}\text { F: HEX-GCCCCCTTCTCAACCCACTA } \\
\text { R: TGCTTTCCAAAGCGAACCGT }\end{array}$ & $106-120$ & 54.5 & 6 & JQ804789 \\
\hline 5 & $\operatorname{Sin} 143$ & $(\mathrm{GTT})_{7}$ & $\begin{array}{l}\text { F: HEX-AAAGCAGGCCAAACAACACC } \\
\text { R: AGGACGGGGAGGCTTTTGAT }\end{array}$ & $198-246$ & 54.5 & 5 & JQ804797 \\
\hline 6 & $\operatorname{Sin} 147$ & $(\mathrm{TCC})_{9}$ & $\begin{array}{l}\text { F: FAM-AGATCAGACACCAGGAGGACC } \\
\text { R: AAGACGGAGGCAAAGAACGAC }\end{array}$ & $174-232$ & 53.5 & 5 & JQ804801 \\
\hline 7 & $\operatorname{Sin} 152$ & $(\mathrm{AG})_{8} \mathrm{~A}(\mathrm{AG})_{13}$ & $\begin{array}{l}\text { F: HEX-TGCGCCACTTTACTGATGGG } \\
\text { R: GCATTAACCAAACCCGCGA }\end{array}$ & $185-240$ & 54.5 & 8 & JQ804806 \\
\hline 8 & $\operatorname{Sin} 156$ & $(\mathrm{AC})_{13}$ & $\begin{array}{l}\text { F: FAM-TAGGAGGCTTTACAACCGGC } \\
\text { R: ATGACCAGCCTCAGGTGTCT }\end{array}$ & $188-205$ & 53.5 & 2 & JQ804810 \\
\hline 9 & EST1 & $(\mathrm{CA})_{10}$ & $\begin{array}{l}\text { F: FAM-CCAGCCAACAACCATAAAG } \\
\text { R: CCCAGGTAGAAGACCGTGA }\end{array}$ & $200-240$ & 58.0 & 6 & GR477481 \\
\hline 10 & EST-6 & $(\mathrm{TG})_{11}(\mathrm{GT})_{6}$ & $\begin{array}{l}\text { F: HEX-TCCCAGTAGCATTCAAAC } \\
\text { R: TGCATACATACACCCACA }\end{array}$ & $135-198$ & 61.0 & 8 & GR477337 \\
\hline 11 & EST-19 & $(\mathrm{CT})_{7}(\mathrm{CT})_{11}(\mathrm{TG})_{14}$ & $\begin{array}{l}\text { F: GACAGTACAAGTAAGGCACA } \\
\text { R: GTCGCATAAATATCACAGAA }\end{array}$ & $285-336$ & 61.0 & 7 & GR476867 \\
\hline 12 & EST-21 & $(\mathrm{CA})_{15}$ & $\begin{array}{l}\text { F: ROX-AGTGAGGTGGAGGGGTGA } \\
\text { R: TACGTTGCCGATGAAAGC }\end{array}$ & $128-230$ & 63.0 & 17 & GR476843 \\
\hline 13 & EST-33 & $(\mathrm{AC})_{13}$ & $\begin{array}{l}\text { F: ROX-CACTGTGCTCAACGTACT } \\
\text { R: GTGACATTTAGCCCATAA }\end{array}$ & $126-144$ & 63.0 & 4 & GR476286 \\
\hline 14 & Mar9 & $(\mathrm{GT})_{21}$ & $\begin{array}{l}\text { F: HEX-GACATCACCAATACCTCCTGACACG } \\
\text { R:TACACACGCATGGAGTATCTGGATC }\end{array}$ & $232-397$ & 52.0 & 19 & GU324513 \\
\hline
\end{tabular}

\section{Polymerase chain reaction (PCR) amplification}

The total volume $(20 \mu \mathrm{L})$ contained $2.0 \mu \mathrm{L} 10 \mathrm{X}$ buffer, $0.8 \mu \mathrm{L} 25 \mathrm{mM} \mathrm{MgCl}_{2}, 0.4 \mu \mathrm{L}$ $10 \mu \mathrm{M}$ dNTP, $0.4 \mu \mathrm{L} 20 \mu \mathrm{M}$ of each primer, $40 \mathrm{ng}$ genomic DNA, and $1 \mathrm{U}$ Taq enzyme. The PCR consisted of 5 min of pre-denaturing at $94^{\circ} \mathrm{C}$, followed by 35 cycles at $94^{\circ} \mathrm{C}$ for $30 \mathrm{~s}$, $55^{\circ} \mathrm{C}$ for $30 \mathrm{~s}, 72^{\circ} \mathrm{C}$ for $30 \mathrm{~s}$, and a final extension for $10 \mathrm{~min}$ at $72^{\circ} \mathrm{C}$. STRs were analyzed based on the sizes of the amplified fragment, and STR genotyping was conducted by Sangon Biotech (Shanghai, China). The STR sequences were analyzed using electrophoresis (Hai Qite Analytical Instruments Co. Ltd.), a gel imaging system (Gene Genius Co. Ltd.), and a 3730XL sequence analyzer (ABI, USA). The genotype of each $S$. chuatsi individual was determined according to the size of each amplified fragment.

\section{Data analysis}

The genotype of each fish was determined by STR according to the size of the band (allele). Alleles were sorted in descending alphabetical order and analyzed with POPGENE 32. Each population of $S$. chuatsi was analyzed for number of alleles $\left(N_{\mathrm{A}}\right)$, effective num- 
ber of alleles $\left(N_{\mathrm{E}}\right)$, observed heterozygosity $\left(H_{\mathrm{O}}\right)$, expected heterozygosity $\left(H_{\mathrm{E}}\right)$, the genetic similarity index $(I)$, genetic distance between populations $\left(D_{S}\right)$, and genetic similarity $(S)$. The FSTAT software was used to calculate the genetic differentiation index $\left(F_{\mathrm{ST}}\right)$, and a phylogenetic tree was constructed by MEGA5 using Nei's genetic distance (Tamura et al., 2011). The CERVUS 3.0 software was used to calculate the polymorphism information content (PIC) (Kalinowski et al., 2007), and $F_{\mathrm{ST}}$ analysis and an analysis of molecular variance (AMOVA) were performed using ARLEQUIN 3.1 (Excoffier and Lischer, 2010; Takeda et al., 2013). The population genetic structure was analyzed by the STRUCTURE 2.3 software, and the optimal $\mathrm{K}$ value (number of clusters) was analyzed using the maximum likelihood method (Evanno et al., 2005; Qin et al., 2014).

\section{RESULTS}

\section{Microsatellite polymorphisms and genetic diversity}

All 14 selected primers amplified fragments from the DNA isolated from 149 individual fish belonging to the five populations. These fragments exhibited different levels of polymorphism (Table 2). $N_{\mathrm{A}}$ ranged from 3 to $15, N_{\mathrm{E}}$ from 1.28 to 5.51, the Shannon Index (SI) from 0.392 to $2.078, H_{\mathrm{O}}$ from 0.128 to $0.98, H_{\mathrm{E}}$ from 0.220 to 0.822 , and the PIC from 0.396 to 0.778 . Except for the locus $\sin 156$ that had a PIC of 0.396 and was moderately polymorphic $(0.25<$ PIC $<0.5)$, the loci exhibited high levels of polymorphism $(\mathrm{PIC}>0.5)$.

Table 2. Number of alleles, heterozygosity and polymorphic information content of in Siniperca chuatsi 14 microsatellite loci.

\begin{tabular}{lcccccc}
\hline Locus & $\begin{array}{c}\text { Number of } \\
\text { allele }\left(N_{\mathrm{A}}\right)\end{array}$ & $\begin{array}{c}\text { Effective number } \\
\text { of alleles }\left(N_{\mathrm{E}}\right)\end{array}$ & $\begin{array}{c}\text { Shannon } \\
\text { index }(\mathrm{SI})\end{array}$ & $\begin{array}{c}\text { Observed } \\
\text { heterozygosity }\left(H_{\mathrm{O}}\right)\end{array}$ & $\begin{array}{c}\text { Expected } \\
\text { heterozygosity }\left(H_{\mathrm{E}}\right)\end{array}$ & $\begin{array}{c}\text { Polymorphic information } \\
\text { content }(\text { PIC) }\end{array}$ \\
\hline EST1 & 6 & 4.83 & 1.646 & 0.541 & 0.796 & 0.597 \\
EST6 & 5 & 2.37 & 1.000 & 0.980 & 0.581 & 0.579 \\
EST19 & 5 & 2.56 & 1.087 & 0.226 & 0.611 & 0.720 \\
EST21 & 8 & 5.05 & 1.702 & 0.980 & 0.805 & 0.617 \\
EST23 & 4 & 2.43 & 1.022 & 0.569 & 0.590 & 0.735 \\
Mar9 & 7 & 3.71 & 1.514 & 0.356 & 0.733 & 0.701 \\
$\sin 112$ & 4 & 3.24 & 1.232 & 0.963 & 0.694 & 0.775 \\
$\sin 116$ & 8 & 3.85 & 1.595 & 0.696 & 0.743 & 0.708 \\
$\sin 130$ & 4 & 1.76 & 0.807 & 0.401 & 0.433 & 0.702 \\
$\sin 134$ & 7 & 2.66 & 1.308 & 0.128 & 0.626 & 0.535 \\
$\sin 143$ & 3 & 1.28 & 0.392 & 0.237 & 0.220 & 0.672 \\
$\sin 147$ & 6 & 3.21 & 1.248 & 0.705 & 0.691 & 0.778 \\
$\sin 152$ & 15 & 5.51 & 2.078 & 0.784 & 0.822 & 0.743 \\
$\sin 156$ & 3 & 2.07 & 0.811 & 0.483 & 0.518 & 0.396 \\
Average value & 6.07 & 3.18 & 1.246 & 0.575 & 0.633 & 0.661 \\
\hline
\end{tabular}

The genetic diversity of the five populations is shown in Table 3. The HG wild population had the highest $N_{\mathrm{A}}(5.29)$ and $N_{\mathrm{E}}$ (3.23), while the JM population had the lowest $N_{\mathrm{A}}$ (4.21) and $N_{\mathrm{E}}$ (2.78). The HG wild population had the highest SI value (1.197), while the HZL population had the lowest (1.096). The FS population had the highest $H_{\mathrm{O}}(0.596)$, while the NJ population had the lowest (0.494). The highest $H_{\mathrm{E}}$ was in the $\mathrm{HG}$ wild population (0.633), and the lowest was in the FS population (0.608). The highest PIC was in the HG wild population $(0.574)$, while the lowest was in the JM population (0.544). These results suggest that all five 
populations have relatively high genetic diversity, with the greatest genetic diversity in the wild population.

Table 3. Genetic diversity of five Siniperca chuatsi population.

\begin{tabular}{lccccc}
\hline Genetic diversity index & Foshan (FS) & Jiangmen (JM) & Nanjing (NJ) & Hongze Lake (HZL) & Huanggang (HG) \\
\hline$N_{\mathrm{A}}$ & 5.07 & 4.21 & 4.79 & 4.36 & 5.29 \\
$N_{\mathrm{E}}$ & 2.84 & 2.78 & 2.96 & 2.91 & 1.096 \\
$\mathrm{I}$ & 1.143 & 1.110 & 1.112 & 0.566 & 1.197 \\
$H_{\mathrm{O}}$ & 0.596 & 0.576 & 0.494 & 0.616 & 0.536 \\
$H_{\mathrm{E}}$ & 0.608 & 0.624 & 0.626 & 0.551 & 0.633 \\
$\mathrm{PIC}$ & 0.550 & 0.544 & 0.563 & & 0.574 \\
\hline
\end{tabular}

\section{Inter-population genetic differentiation and analysis of genetic distance}

$F_{\mathrm{ST}}$ values ranged between 0.0027 and 0.0814 (Table 4), suggesting that there was moderate or low differentiation $\left(F_{\mathrm{ST}}<0.05\right)$. The lowest genetic differentiation was between the HG wild population and the NJ population $\left(F_{\mathrm{ST}}=0.0027\right)$. The highest genetic differentiation was between the HG wild population and the JM population $\left(F_{\mathrm{ST}}=0.0814\right)$, but was still only at a moderate level $\left(0.05<F_{\mathrm{ST}}<0.15\right)$ (Table 4$)$. The results of the AMOVA indicate that only $5.44 \%$ of the genetic variation was between the populations, while $94.56 \%$ was within the populations. These results suggest that genetic variation between individual $S$. chuatsi was higher than that between populations (Table 5).

Table 4. Fixation index $\left(F_{\mathrm{ST}}\right)$ for five Siniperca chuatsi populations.

\begin{tabular}{lccccc}
\hline & Foshan (FS) & Jiangmen (JM) & Nanjing (NJ) & Hongze Lake (HZL) & Huanggang (HG) \\
\hline Foshan (FS) & $* * * *$ & - & - & - & - \\
Jiangmen (JM) & 0.0147 & $* * * *$ & - & - & - \\
Nanjing (NJ) & 0.0731 & 0.0814 & $* * * *$ & - & - \\
Hongze Lake (HZL) & 0.0302 & 0.0556 & 0.0759 & $* * * *$ & - \\
Huanggang (HG) & 0.0709 & 0.0714 & 0.0027 & 0.0681 & $* * * *$ \\
\hline
\end{tabular}

Table 5. AMOVA analysis among five Siniperca chuatsi populations.

\begin{tabular}{lrccc}
\hline Source of variation & d.f. & Sum of squares & Variance components & Percentage variation \\
\hline Among populations & 4 & 72.020 & 0.24422 & 5.44065 \\
Within populations & 287 & 1214.182 & 4.24454 & $94.55935^{* *}$ \\
Total & 291 & 1286.202 & 4.48876 & \\
\hline
\end{tabular}

**Highly significant $(\mathrm{P}<0.01)$ after 1023 permutation tests.

The inter-population Nei's genetic distance $\left(D_{A}\right)$ ranged between 0.0365 and 0.1894 and $S$ ranged between 0.8275 and 0.9641 (Table 6). The lowest $D_{A}(0.0365)$ and the highest $S$ (0.9641) were between the NJ population and the HG wild population. In contrast, the highest $D_{A}(0.1894)$ and lowest $S(0.8275)$ were between the JM population and the HG wild population. Phylogenetic analysis using the unweighted pair group method with arithmetic mean (UPGMA) revealed that the five populations could be divided into two groups, one group containing the NJ and HG populations and the other containing the FS, JM, and HZL populations (Figure 2). 
Table 6. Nei's genetic distance (below diagonal) and genetic similarity (above diagonal) of five Siniperca chuatsi populations.

\begin{tabular}{lccccc}
\hline & Foshan (FS) & Jiangmen (JM) & Nanjing (NJ) & Hongze Lake (HZL) & Huanggang (HG) \\
\hline Foshan (FS) & $* * * *$ & 0.9451 & 0.8610 & 0.9325 & 0.8605 \\
Jiangmen (JM) & 0.0565 & $* * * *$ & 0.8275 & 0.8735 & 0.8371 \\
Nanjing (NJ) & 0.1496 & 0.1894 & $* * * *$ & 0.8533 & 0.9641 \\
Hongze Lake (HZL) & 0.0699 & 0.1353 & 0.1587 & $* * * *$ & 0.8607 \\
Huanggang (HG) & 0.1503 & 0.1778 & 0.0365 & 0.1501 & $* * *$ \\
\hline
\end{tabular}
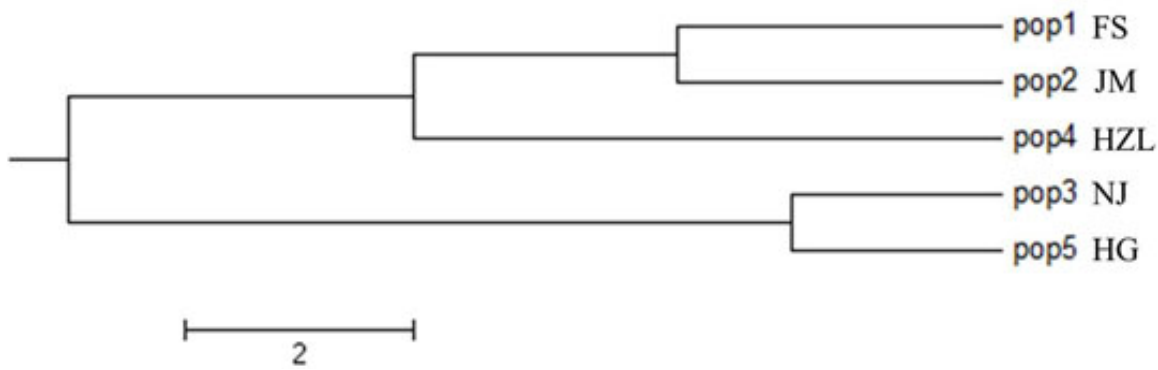

Figure 2. A UPGMA dendrograrn of 5 mandarin fish populations based on Nei's genetic distance.

\section{Population genetic structure analysis}

Clustering was conducted using the STRUCTURE software, with a hypothetical K value of between 2 and 5, using 10 replicates. Bayesian analysis, based on the parameters corresponding to each hypothetical $\mathrm{K}$ value, revealed that a $\mathrm{K}$ value of 2 occurred in the plateau phase, suggesting that all of the $S$. chuatsi included in this study could be divided into two clusters. Figure 3 shows that the FS, JM, and HZL populations formed one group and the HG and $\mathrm{NJ}$ populations formed another.

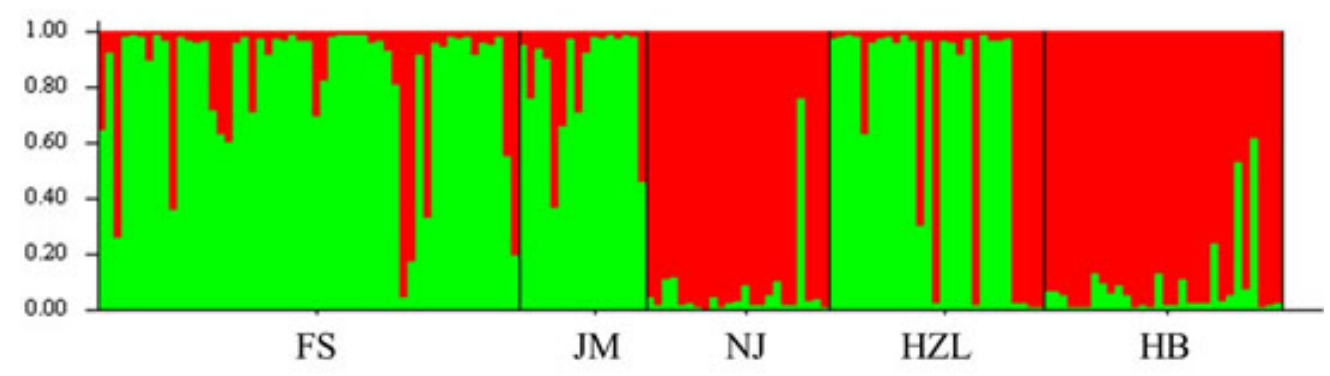

Figure 3. Cluster analysis based on 14 microsatellite loci for the Siniperca chuatsi specimens from STRUCTURE $(\mathrm{K}=2)$.

\section{DISCUSSION}

The PIC value indicates the genetic variation and polymorphism of an allele in a population (Sanjay et al., 2000). In this study, the PIC of 14 microsatellite loci ranged from 0.396 to 0.778 . According to Botstein et al. (1980), a locus is classified as highly polymorphic 
when the PIC is higher than 0.5 , moderately polymorphic when the PIC is higher than 0.25 but lower than 0.5 , and weakly polymorphic when the PIC is lower than 0.25 . Our results indicate that 13 loci were highly polymorphic and one $(\sin 156)$ was moderately polymorphic.

Heterozygosity is an important indicator of population genetic variation. $H_{\mathrm{O}}$ is strongly affected by sample size, and $H_{\mathrm{E}}$ more accurately reflects population genetic diversity (Bao et al., 2007). In this study, the average $H_{\mathrm{E}}$ ranged between 0.608 and 0.633 , and the highest $H_{\mathrm{E}}$ was in the HG wild population $(0.633)$. The $H_{\mathrm{O}}$ and $H_{\mathrm{E}}$ results demonstrate that all five populations have high genetic diversity, indicating that they have the genetic basis for further breeding. It should be noted that genetic diversity in the wild population was higher than that in the four farmed populations, suggesting that the wild population has greater potential for breeding. These results are consistent with those from previous studies that found that a wild population in Poyang Lake exhibited higher levels of genetic polymorphism than a farmed population (Fang et al., 2005; Yu et al., 2012). Our results also indicate that long-term farming reduces the genetic diversity of $S$. chuatsi. To avoid inbreeding, more wild populations should be used as parents during the breeding process, in order to ensure a high genetic diversity of the breeding population.

Genetic distance and similarity are parameters that describe the genetic relationship between two populations (Cui et al., 2012). Our results show that the NJ population had the shortest genetic distance $\left(D_{A}=0.0339\right)$ and the highest genetic similarity $(S=0.9667)$ to the HG wild population, indicating that the closest relationship was between the NJ population and the wild population. The FS population had the greatest genetic distance $\left(D_{A}=0.1778\right)$ and the lowest genetic similarity $(S=0.8371)$ to the HG wild population, indicating that the weakest relationship was between the FS population and the wild population. The $F_{\mathrm{ST}}$ analysis obtained similar results, and the phylogenetic tree clearly demonstrates this relationship. The NJ population may have been introduced from the Yangtze River, and therefore had a similar genetic structure to the HG wild population, which was collected from the middle reaches of the river. Recently, inbreeding has become a concern. Some fish breeding companies catch wild $S$. chuatsi fry from the Yangtze River and breed them in ponds. Sexually mature adults are then chosen as parents for breeding, in order to enhance the genetic diversity of S. chuatsi.

The STRUCTURE software performs population simulation analysis based on an individual's genetic composition. It is not affected by the number of individuals in a population, and is an ideal tool to analyze population genetic structure (Kalinowski et al., 2007; Fu et al., 2013). All of the individual $S$. chuatsi in this study could be divided into two geographical groups, confirming the UPGMA clustering results. The genetic structure results are also consistent with the genetic differentiation results. The HG wild population had a similar genetic structure to the NJ population, and the two farmed populations in Guangdong had similar genetic structures to the HZL population. Gene flow may have occurred between the farmed populations and the wild population. These results also suggest that breeding companies should use wild S. chuatsi as parents, in order to increase the genetic diversity of farmed populations.

In conclusion, this study provides evidence that farmed $S$. chuatsi populations have lower genetic diversity than wild populations. However, the farmed populations have maintained a relatively high genetic diversity, suggesting that they have the genetic basis for further breeding. Genetic differentiation between the farmed and wild populations was high, indicating that long-term artificial propagation can reduce genetic diversity in farmed populations. Therefore, wild S. chuatsi resources should be introduced during the breeding process to 
maintain the genetic diversity of farmed populations. In addition, $S$. chuatsi selective breeding should be developed in order to obtain novel varieties that exhibit rapid growth and anti-disease characteristics, to ensure the sustainable development of the $S$. chuatsi aquaculture industry.

\section{Conflicts of interest}

The authors declare no conflict of interest.

\section{ACKNOWLEDGMENTS}

Research supported by grants from the Science and Technology Project of Guangzhou (\#20134411115) and the State Administration of Foreign Experts Affairs (\#20140326016).

\section{REFERENCES}

Bao WB, Shu JT, Xu SH and Li HF (2007). Effects of sample size and sex ratio on various genetic diversity measures with microsatellite markers. Chin. J. Anim. Sci. 43: 6-9.

Botstein D, White RL, Skolnick M and Davis RW (1980). Construction of genetic linkage map in man using restriction fragment length polymorphisms. Am. J. Hum. Genet. 32: 314-331.

Chauhan T and Rajiv K (2010). Molecular markers and their applications in fisheries and aquaculture. Adv. Biosci. Biotechnol. 1: 281-291.

Chen DX, Chu WY, Liu XL, Nong XX, et al. (2012). Phylogenetic studies of three sinipercid fishes (Perciformes: Sinipercidae) based on complete mitochondrial DNA sequences. Mitochondrial DNA 23: 70-76.

Cui L, Xie CX, Li YH, Yu YY, et al. (2012). Analysis of genetic diversity among four different channel catfish populations by using microsatellite markers. J. Huazhong Agr. Univ. 31: 744-751.

Evanno G, Regnaut S and Goudet J (2005). Detecting the number of clusters of individuals using the software STRUCTURE: a simulation study. Mol. Ecol. 14: 2611-2620.

Excoffier L and Lischer H (2010). Arlequin suite version 3.5: a new series of programs to perform population genetics analyses under Linux and Windows. Mol. Ecol. Resour. 10: 564-567.

Fang PW and Chong LT (1932). Study on the fishes referring to Siniperca of China. Sinensia 2: 137-200.

Fang ZQ, Chen J, Zheng WB, Wu YY, et al. (2005). RAPD analysis of wild population and cultivated population in Siniperca chuatsi Basilewsky. J. Dalian Fish. Univ. 3: 16-19.

Fu JJ, Li JL, Shen YB, Wang RQ, et al. (2013). Genetic variation analysis of wild populations of grass carp (Ctenopharyngodon idella) using microsatellite markers. Hereditas 35: 192-201.

He JG, Zeng K, Weng SP and Chan SM (2002). Experimental transmission, pathogenicity and physical chemical properties of infectious spleen and kidney necrosis virus (ISKNV). Aquaculture 204: 11-24.

Kalinowski T, Taper ML and Marshall TC (2007). Revising how the computer program cervus accommodates genotyping error increases success in paternity assignment. Mol. Ecol. 16: 1099-1106.

Kumar P, Gupta VK, Misra AK, Modi DR, et al. (2009). Potential of molecular markers in plant biotechnology. Plant Omics 2: 141-162.

Liu ZJ and Cordes JF (2004). DNA marker technologies and their applications in aquaculture genetics. Aquaculture 5: 1-37.

Liu X, Luo W, Zeng C, Wang W, et al. (2011). Isolation of new 40 microsatellite markers in mandarin fish (Siniperca chuatsi). Int. J. Mol. Sci. 12: 4180-4189.

Mei QL, Liu Z, Zhang XW, Xie DZ, et al. (2010). Analysis of genetic diversity between protospecies and cultured populations of Siniperca chuatsi based on microsatellite markers. Genome Appl. Biol. 29: 266-272.

Powell W, Morgante M, Andre C, Hanafey M, et al. (1996). The comparison of RFLP, RAPD, AFLP and SSR (microsatellite) markers for germplasm analysis. Mol. Breed. 2: 225-238.

Qin Y, Sun DQ, Xu TJ, Liu XZ, et al. (2014). Genetic diversity and population genetic structure of the miiuy croaker, Miichthys miiuy, in the East China Sea by microsatellite markers. Genet. Mol. Res. 13: 10600-10606.

Qu CM, Liang XF, Huang W and Cao L (2012). Isolation and characterization of 46 novel polymorphic EST-simple sequence repeats (SSR) markers in two Sinipercine fishes (Siniperca) and cross-species amplification. Int. J. Mol. Sci. 13: 9534-9544. 
Sanjay S, Hemant T and Robert CE (2000). On estimating the heterozygosity and polymorphism information content value. Theor. Popul. Biol. 5: 265-271.

Takeda M, Kusumi J, Mizoiri S, Aibara M, et al. (2013). Genetic structure of pelagic and littoral cichlid fishes from Lake Victoria. PLoS One 8: e74088.

Tamura K, Peterson D, Peterson N, Stecher G, et al. (2011). MEGA 5: molecular evolutionary genetics analysis using maximum likelihood, evolutionary distance, and maximum parsimony methods. Mol. Biol. Evol. 28: 2731-2739.

Tian CX, Yang M, Liang XF, Cao L, et al. (2013). Population genetic structure of Siniperca chuatsi in the middle reach of the Yangtze River inferred from mitochondrial DNA and microsatellite loci. Mitochondrial DNA 8: 1-8.

Yu R, Liang XF, Yi TL, Zhang J, et al. (2012). Economic traits and genetic diversity of three cultured mandarin fish Siniperca chuatsi populations. Fish. Sci. 9: 511-515.

Zane L, Bargelloni L and Patarnello T (2002). Strategies for microsatellite isolation: a review. Mol. Ecol. 11: 1-16.

Zhao JL, Li CH, Zhao LL, Wang WW, et al. (2008). Mitochondrial diversity and phylogeography of the Chinese perch, Siniperca chuatsi (Perciformes: Sinipercidae). Mol. Phylogenet. Evol. 49: 399-404.

Zhou CW, Yang Q and Cai D (1988). On the classification and distribution of the sinipercinae fishes (Family serranidae). Zool. Res. 9: 113-125. 